\title{
The love-hate relationship between Ras and Notch
}

\author{
Meera V. Sundaram \\ Department of Genetics, University of Pennsylvania, Philadelphia, Pennsylvania 19104, USA
}

\begin{abstract}
The Ras and Notch signaling pathways are used over and over again during development to control many different biological processes. Frequently, these two signaling pathways intersect to influence common processes, but sometimes they cooperate and sometimes they antagonize each other. The Caenorhabditis elegans vulva and the Drosophila eye are two classic paradigms for understanding how Ras and Notch affect cell fates, and how the two pathways work together to control biological pattern. Recent advances in these systems reveal some of the mechanisms by which Ras and Notch can interact. Similar types of interactions in mammals may be important for determining whether and how alterations in Ras or Notch lead to cancer.
\end{abstract}

A relatively small number of intercellular signaling pathways are used over and over again during development to control many different biological processes. Inevitably, these signaling pathways tend to intersect to influence common sets of cells and common processes. An important question is how cells are able to integrate these different (and sometimes conflicting) signals and respond to them in appropriate and specific ways. Signal integration and "cross-talk" also determine how cells respond when signaling pathways become inappropriately activated, as in many cancers.

The Ras and Notch signaling pathways are two examples that clearly illustrate the larger problem. Over the last decades, we have learned a lot about the molecular components of these highly conserved pathways and their importance in cancer, and about the many normal developmental processes that require one or both pathways. However, we have only a limited understanding of how these very common signaling pathways can affect these different developmental processes in such specific ways. Moreover, when the Ras and Notch pathways intersect, as they often do, they sometimes cooperate and sometimes antagonize each other. The contextual factors that govern this love-hate relationship are poorly understood.

[Keywords: C. elegans; Drosophila; Notch; Ras; signaling] E-MAIL sundaram@mail.med.upenn.edu; FAX (215) 573-4527. Article and publication are at http://www.genesdev.org/cgi/doi/10.1101/ gad. 1330605
In this review, I first highlight some of the mechanisms that are thought to control specific responses to Ras or Notch signaling. I then focus on two classic developmental genetic systems, the Caenorhabditis elegans vulva and the Drosophila eye, that have been used to study the Ras and Notch signaling pathways and the relationships between these pathways. The developmental studies in the worm and fly suggest a variety of mechanisms that could explain the cooperative and antagonistic relationships observed between Ras and Notch in other developmental systems and during tumorigenesis.

\section{The Ras pathway}

Ras is a small GTPase that cycles between an inactive, GDP-bound state and an active, GTP-bound state. In mammals, Ras appears to be a central player in multiple signaling pathways: Ras can be activated by a wide variety of upstream signals, and Ras-GTP can bind and activate multiple downstream targets (Malumbres and Barbacid 2002; Repasky et al. 2004). However, in C. elegans and Drosophila, Ras acts primarily within a canonical receptor tyrosine kinase (RTK)-Ras-mitogen-activated protein kinase (MAPK)/extracellular signal-regulated kinase (ERK) pathway (Table 1; Wassarman et al. 1995; Prober and Edgar 2002; Sundaram 2005). The epidermal growth factor receptor (EGFR) is one major RTK that signals through Ras and ERK. The main features of such signaling pathways have been reviewed extensively (Lewis et al. 1998; Schlessinger 2000) and are summarized in Figure 1.

Transcription factors of the Ets family are key ERK targets in mammals, worms, and flies (Sharrocks 2001). In mammals, ERK phosphorylation converts the Ets domain protein Elk-1 from a transcriptional repressor to a transcriptional activator. In the absence of Ras signaling, Elk-1 is sumoylated and associated with transcriptional repressor complexes (Yang et al. 2003; Yang and Sharrocks 2004). After phosphorylation by ERK, Elk-1 becomes desumoylated, binds the Mediator component Sur-2, and activates transcription (Stevens et al. 2002). In C. elegans, the Elk-1-related protein LIN-1 appears to be regulated by similar mechanisms, although its repressor function is better characterized while its activator function is inferred based on the properties of sur-2 mutants 
Table 1. Core components of the RTK-Ras-ERK pathway in worms, flies, and mammals

\begin{tabular}{|c|c|c|c|}
\hline Component & C. elegans & Drosophila & Mammals \\
\hline Ligand & LIN-3 & Spitz, others & $\begin{array}{l}\text { EGF, TGF } \alpha, \\
\text { others }\end{array}$ \\
\hline RTK & LET-23 & EGFR & EGFR \\
\hline Adaptor & SEM-5 & Drk & Grb2 \\
\hline $\begin{array}{l}\text { Exchange } \\
\text { factor }\end{array}$ & SOS-1 & Sos & Sos \\
\hline Ras & LET-60 & Ras 1 & $\begin{array}{c}\text { K-Ras, H-Ras, } \\
\text { N-Ras }\end{array}$ \\
\hline Scaffold & KSR-1, KSR-2 & KSR & KSR-1, KSR-2 \\
\hline Raf & LIN-45 & Draft1 & $\begin{array}{l}\text { B-Raf, C-Raf, } \\
\text { A-Raf }\end{array}$ \\
\hline MEK & MEK-2 & Dsor1 & Mek1, Mek2 \\
\hline ERK & MPK-1 & Rolled & Erk1, Erk2 \\
\hline Ets factor & LIN-1 & Yan, Pointed & Elk1, others \\
\hline Corepressors & SMO-1, MEP-1 & $?$ & Sumo \\
\hline Coactivator & SUR-2 & $?$ & Sur2 \\
\hline
\end{tabular}

See text for discussion and references.

(Beitel et al. 1995; Singh and Han 1995; Jacobs et al. 1999; Howard and Sundaram 2002; Leight et al. 2005). In Drosophila, two separate Ets domain proteins, Yan and Pointed, function as repressor and activator, respectively: ERK phosphorylation alleviates Yan repressor function and stimulates Pointed activator function (Brunner et al. 1994; O'Neill et al. 1994; Rebay and Rubin 1995; Gabay et al. 1996). The SAM domain protein MAE is an important modulator that controls the balance between Yan and Pointed activities (Baker et al. 2001; Tootle et al. 2003; Qiao et al. 2004; Vivekanand et al. 2004; Song et al. 2005). In all these organisms, ERK phosphorylation of Ets transcription factors causes a switch from transcriptional repression to transcriptional activation of Ets target genes.

Ets transcription factors can control the expression of many different types of target genes. ERK also has many potential targets other than Ets factors. These properties help to explain how the Ras/ERK pathway can affect so many different biological processes.

\section{The Notch pathway}

Notch is a single-pass transmembrane receptor that acts in an equally well conserved but much shorter signaling pathway (Fig. 2; Table 2; Greenwald 1998; ArtavanisTsakonas et al. 1999; Kadesch 2004). Its ligands are proteins of the DSL (Delta/Serrate/LAG-2) family, most of which are transmembrane proteins. Ligand binding to Notch triggers its proteolysis and releases a C-terminal Notch fragment. This Notch intracellular domain (NICD) fragment translocates to the nucleus to promote target gene transcription.

Transcription factors of the CSL /CBF/Suppressor of Hairless/LAG-1) family are key mediators of Notch signaling in mammals, worms, and flies (Lai 2002). In the absence of Notch signaling, CSL proteins associate with a corepressor complex and repress target gene transcription. The specific components of this corepressor com- plex appear to differ between mammals and flies (Table 2) and are completely unknown in worms, but histone deacetylases are a common feature (Kao et al. 1998; Chen et al. 1999). When Notch becomes active, NICD displaces the corepressor complex and recruits a coactivator complex containing Mastermind/LAG-3/SEL-8 (Doyle et al. 2000; Petcherski and Kimble 2000; Wu et al. 2000; Kitagawa et al. 2001), allowing CSL to activate target gene transcription. Thus Notch signaling causes a switch from transcriptional repression to transcriptional activation of CSL target genes.

CSL transcription factors may control the expression of different types of target genes, helping to explain how Notch signaling can affect so many different biological processes. However, the best understood CSL targets in Drosophila and mammals are basic helix-loop-helix (bHLH) proteins of the Hairy/E(spl) (HES) family (Bailey and Posakony 1995; Iso et al. 2003). Very recently, a divergent set of bHLH proteins (the REF-1 family) was identified as CSL targets in C. elegans (Neves and Priess 2005). All of these bHLH proteins seem to function as transcriptional repressors, and utilize the corepressor Groucho. The ability of Notch signaling to up-regulate these repressors may explain many instances where Notch seems to act as an "anti-differentiation" signal.

\section{Inductive signaling vs. lateral specification}

Both Ras and Notch mediate many inductive signaling events in which one cell type signals to another distinct

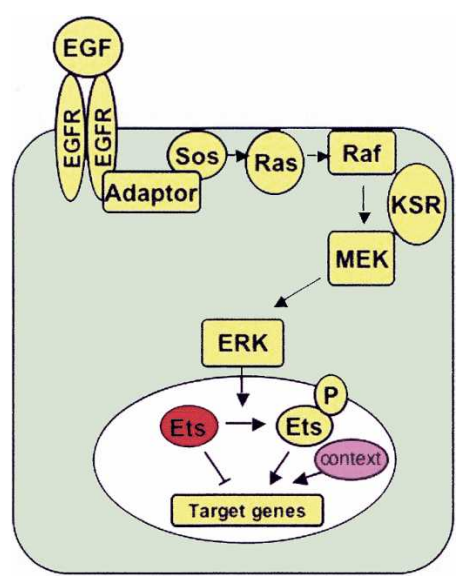

Figure 1. The RTK-Ras-ERK pathway. Binding of an EGF ligand to EGFR causes the receptor to dimerize and autophosphorylate tyrosine residues in its cytoplasmic domain. These phospho-tyrosine residues then serve as docking sites for an adaptor protein that recruits the guanine nucleotide exchange factor Sos to activate Ras. Ras-GTP binds to the serine/threonine kinase Raf and facilitates Raf kinase activation. Raf phosphorylates and activates the dual specificity kinase MEK, and MEK phosphorylates and activates the serine/threonine kinase ERK. The scaffold protein KSR is essential for signal propagation through this kinase cascade. Once activated, ERK may phosphorylate numerous targets, including Ets domain transcription factors, to affect target gene transcription. Contextual factors (purple) determine the specific targets used. 
Table 2. Core components of the Notch pathway in worms, flies, and mammals

\begin{tabular}{llll}
\hline Component & \multicolumn{1}{c}{ C. elegans } & \multicolumn{1}{c}{ Drosophila } & \multicolumn{1}{c}{ Mammals } \\
\hline DSL Ligands & LAG-2, APX-1 DSL-1 & Delta, Serrate & DLL1, DLL3, DLL4, JAG1, JAG2 \\
Notch Receptor & LIN-12, GLP-1 & Notch & Notch 1-4 \\
CSL factor & LAG-1 & Su(H) & CBF \\
Corepressors & ? & Hairless, Groucho, dCtBP, SMRTER & SMRT, NcoR, CIR \\
Coactivator & LAG-3/SEL-8 & Mastermind & Mastermind \\
\hline
\end{tabular}

See text for discussion and references.

cell type to influence its differentiation or proliferation. However, Notch can also mediate bidirectional signaling between cells of the same type in a process termed lateral inhibition or lateral specification (Greenwald 1998; Artavanis-Tsakonas et al. 1999). The major difference between inductive Notch signaling and lateral inhibition appears to be the initial patterns of DSL and Notch expression. During inductive signaling, one cell type expresses DSL ligand(s) to stimulate Notch in a neighboring but distinct cell type. As discussed below, EGFR/Ras signaling can stimulate expression of DSL ligands, sequentially linking inductive Ras and inductive Notch signaling (Tsuda et al. 2002; Chen and Greenwald 2004). In contrast, during lateral inhibition, two similar undifferentiated cells start out expressing Notch and its DSL ligand(s), but small differences arise and are amplified by various feedback loops such that one cell eventually expresses only Notch and the other expresses only the DSL ligand(s) (Wilkinson et al. 1994; Karp and Greenwald 2003). Thus lateral inhibition eventually leads to the establishment of unidirectional, inductive Notch signaling where no previous hierarchy existed. The end result is that two initially equivalent cells adopt distinct fates.

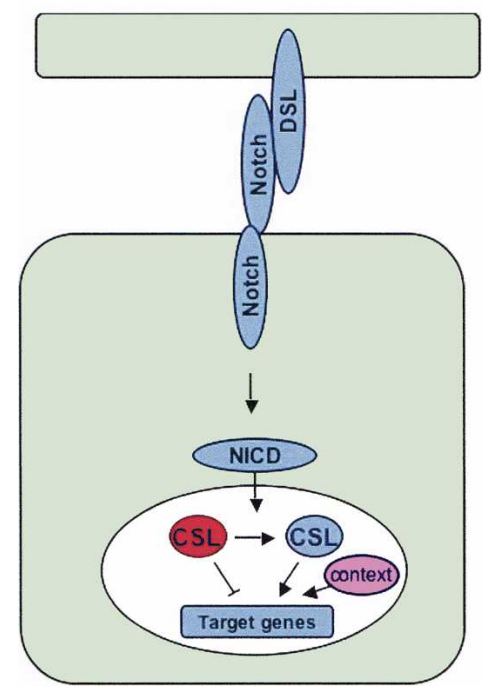

Figure 2. The Notch pathway. Binding of a DSL ligand to Notch triggers its proteolysis and releases the NICD fragment. NICD translocates to the nucleus and interacts with a CSL transcription factor to promote target gene transcription. Contextual factors (purple) determine the specific targets used.

\section{Context-dependent outcomes of signaling}

Both the Ras and Notch pathways are used repeatedly during development to control diverse biological processes. Sometimes these pathways promote growth or proliferation, but sometimes they inhibit it (Serrano et al. 1997; Radtke and Raj 2003; Baonza and Freeman 2005; Firth and Baker 2005; Singh et al. 2005). Sometimes these pathways promote apoptosis, but sometimes they inhibit it (Deftos et al. 1998; Jehn et al. 1999; Morimura et al. 2000; Cox and Der 2003). Often these pathways control differentiation decisions, but they promote differentiation of many widely different cell types. Clearly, then, the specific cellular responses to these pathways are highly context dependent. The challenge is to understand the factors that comprise "context."

Important components of context include other transcription factors that can act cooperatively with Ras- or Notch-stimulated Ets or CSL transcription factors to drive target gene expression (Simon 2000). Often Ets or CSL alone do not seem sufficient to activate target promoters in vivo, so the presence or absence of potential partners controls which specific targets these transcription factors can activate in a given cell (Nellesen et al. 1999; Cooper et al. 2000; Flores et al. 2000; Halfon et al. 2000; Xu et al. 2000; Cave et al. 2005). Such combinatorial action appears to be a general feature of signal-regulated transcription factors, and can generate considerable diversity in downstream gene expression (Barolo and Posakony 2002).

Another component of context is the availability of alternative targets of ERK or Notch (Tan and Kim 1999). ERK can phosphorylate numerous additional targets besides Ets factors, including some other transcription factors with tissue-specific patterns of expression. Notch has also been proposed to have CSL-independent functions, although its alternative targets are less well defined (Ramain et al. 2001; Martinez Arias et al. 2002; Hori et al. 2004). If different tissues express different combinations of potential targets, this could also generate considerable diversity in downstream responses.

A related component of context may be factors that can alter the subcellular localization of signaling components to affect target choice. Although canonical Ras or Notch signaling begins at the plasma membrane and ends in the nucleus, active ERK and active Notch also can be found in endosomal compartments, where they may stimulate distinct downstream targets. For example, the scaffold protein MP1 and its partner p14 di- 
rect active ERK to endosomes (Teis et al. 2002), where it presumably acts on non-Ets targets (Pullikuth et al. 2005). The RING-finger protein Deltex directs Notch to endosomes, where Notch appears to signal in a CSL-independent manner (Hori et al. 2004). Thus, subcellular compartmentalization of active ERK or Notch may control access to specific targets.

A final component of context is the quantitative strength or duration of signaling. There are many instances where different levels of Ras signaling can elicit different biological responses (Greenwood and Struhl 1997; Sabbagh et al. 2001; Murphy et al. 2002, 2004). A classic example is PC12 cells, where low levels of Ras trigger proliferation, but high levels trigger differentiation (Marshall 1995). A similar situation exists in the Drosophila eye, where low levels of Ras support cell growth and survival, but high levels trigger differentiation (Halfar et al. 2001). Notch appears exquisitely sensitive to gene dosage, such that small changes in its expression level have large functional consequences. The variable presence of scaffold proteins that facilitate signaling (Morrison and Davis 2003; Bumeister et al. 2004) or of inhibitors that dampen signaling (Frise et al. 1996; Hubbard et al. 1997; Casci et al. 1999; Irvine 1999; Yeung et al. 1999; Baker et al. 2001; Matheny et al. 2004; Johnson et al. 2005) could contribute significantly to different biological outcomes.

Ras and Notch are themselves components of context. When active Ets and CSL transcription factors are both present in a cell, they may cooperate to activate some target genes that neither can activate alone (Flores et al. 2000). Ras can also influence the expression level, localization, and/or activity of certain Notch pathway components, and vice versa (see below). Thus each pathway can qualitatively or quantitatively influence the other.

\section{Roles of Ras and Notch in development of the $C$.} elegans vulva and the Drosophila eye

The C. elegans vulva and the Drosophila eye are two major systems for the study of the Ras and Notch pathways and their interrelationships (Figs. 3, 4; Sundaram 2004; Voas and Rebay 2004). Both systems are relatively simple, involving small numbers of cells. Worms and flies, unlike mammals, contain only a single Ras gene and one or two Notch genes (Tables 1, 2). The consequences of removing or altering Ras or Notch function can be analyzed with single-cell resolution. Thus it has been possible to tease apart the individual contributions of each pathway to specific developmental steps. Many recent advances in these systems reveal a variety of molecular mechanisms through which the Ras and Notch pathways interact.

Vulval development and eye development have several features in common, which are discussed in more detail below. First, an early step in development involves Notch-mediated lateral inhibition, which controls differentiation of an "organizer cell" that will pattern the re-
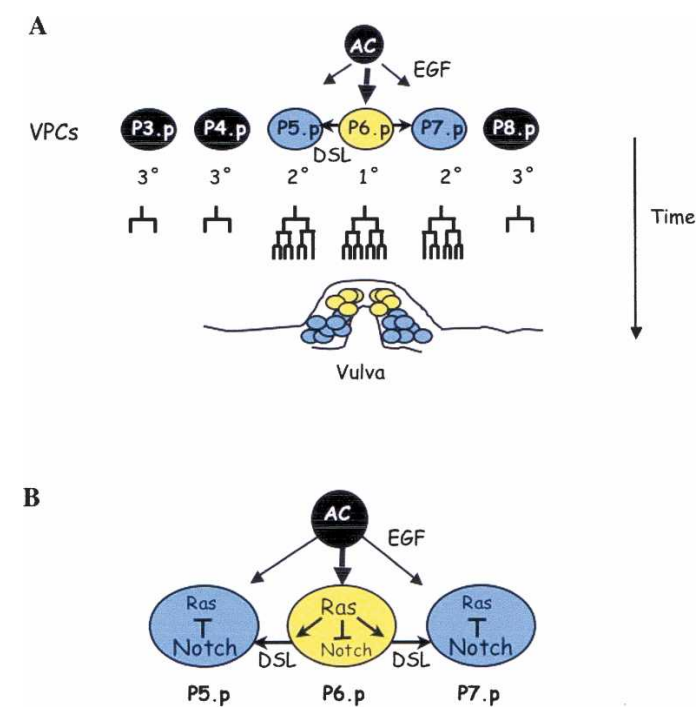

Figure 3. C. elegans vulval development. (A) The six vulval precursor cells (VPCs), specifically named P3.p-P8.p, are ventral epidermal cells positioned adjacently along the anterior-posterior axis. The gonadal anchor cell (AC) is positioned dorsally above P6.p. The AC expresses LIN-3/EGF to activate the EGFR/ Ras/ERK pathway strongly in P6.p and induce the $1^{\circ}$ vulval fate (yellow). P6.p expresses a combination of three DSL ligands to activate LIN-12/Notch in P5.p and P7.p and induce the $2^{\circ}$ vulval fate (blue). Both Ras and Notch activities are low in P3.p, P4.p, and P8.p, which adopt the $3^{\circ}$ fate (black). In $\mathrm{P}(5-7)$.p, the Ras and Notch pathways antagonize each other so that only one of the two pathways is highly active. Low levels of Ras have also been proposed to cooperate with Notch in specifying the $2^{\circ}$ fate (Katz et al. 1995), but the cooperation is not mandatory (Simske and Kim 1995; Yochem et al. 1997) and the molecular mechanisms of cooperation are not known. Subsequent to Ras and Notch signaling, the VPCs go through one or three rounds of cell division, depending on which fate they've adopted. Descendants of the $1^{\circ}$ and $2^{\circ}$ VPCs form the vulva. $(B)$ Ras-Notch interactions in $\mathrm{P}(5-7) \cdot \mathrm{p}$ in more detail. See text and Sternberg (2005) for further details and references.

maining structure. Second, that organizer cell expresses EGF to activate EGFR and the Ras pathway in other nearby cells and to stimulate their differentiation. Third, Ras promotes expression of DSL ligand(s) to activate Notch in nearby cells. Similar patterns of "sequential signaling" have been observed in other Drosophila tissues (Ikeya and Hayashi 1999; Carmena et al. 2002), as well as in mammalian cells (Weijzen et al. 2002; Small et al. 2003; Stella et al. 2005), and may be a frequent feature of Ras and Notch relationships.

Inconsistent relationships between Ras and Notch have been observed within single cells that receive both EGF and DSL signals. In some cases, the two pathways battle for prominence, with one eventually winning out (Shaye and Greenwald 2002; Yoo et al. 2004). In other cases, however, the Ras and Notch pathways cooperate to promote a certain cell fate (Cooper and Bray 2000; Flores et al. 2000; Tomlinson and Struhl 2001). The availability of different cofactors and targets, the relative strength of the two pathways, and the relative timing of 
A
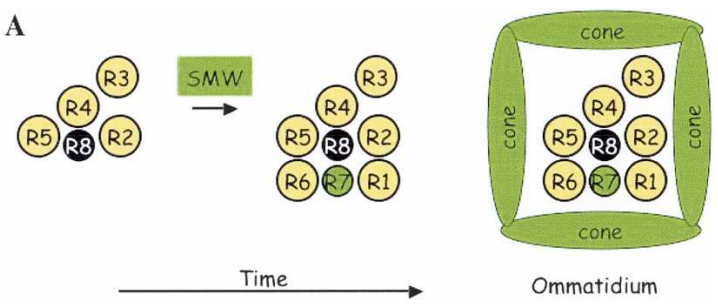

Ommatidium

B

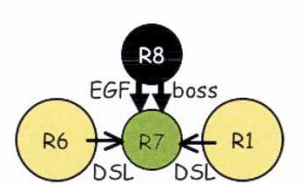

Figure 4. Drosophila eye development. (A) Ommatidia form from a field of equivalent cells within the eye imaginal disc during the third larval instar of development. A wave of differentiation sweeps across the eye disc in conjunction with an observed "morphogenetic furrow." Unpatterned cells ahead of the furrow are dividing asynchronously, but within the furrow, cells arrest in G1. As the furrow passes, R8 photoreceptors arise in an evenly spaced pattern. Subsequently, photoreceptors R2/ R5 and then R3/R4 join R8 to form preclusters. The remaining unspecified cells undergo one synchronous cell division (the SMW) and then join the preclusters in the order R1/R6, then R7, and then the four cone cells (pigment and bristle cells join later and are not shown). Both Ras and Notch activity are low in R8 (black). R8 expresses Spitz/EGF to activate the EGFR/Ras/ERK pathway and induce additional photoreceptor fates (yellow). These R cells then express Delta. Both Ras and Notch signaling cooperate to induce the later R7 and cone cell fates (green). (B) R7 receiving EGF signal from R8 and DSL signal from R1/R6. R7 also receives another growth factor signal, boss, from R8; boss acts through the RTK Sevenless to further boost Ras activity in R7. See text and Voas and Rebay (2004) for further details and references.

pathway activation all contribute to these different outcomes.

\section{C. elegans vulval development}

The C. elegans hermaphrodite vulva is a beautifully simple system for studying Ras and Notch signaling (Sundaram 2004; Sternberg 2005). The vulva originates from just three of six potential vulval precursor cells (VPCs). These six VPCs are each capable of adopting any of three cell fates $\left(1^{\circ}, 2^{\circ}\right.$, or $\left.3^{\circ}\right)$ that are distinguished by different patterns of marker gene expression and different numbers and types of descendants (Fig. 3). A combination of Ras and Notch signaling leads to the invariant $3^{\circ} 3^{\circ} 2^{\circ} 1^{\circ} 2^{\circ} 3^{\circ}$ pattern of VPC fates seen in wild-type animals. Initial differences in VPC positions lead to differences in the relative level and timing of signaling that appear to be critical for cell fate patterning (Sternberg and Horvitz 1989; Fisher et al. 2005).

The gonadal anchor cell (AC) functions as the organizer cell to initiate vulval development (Kimble 1981). AC formation is inhibited by LIN-12/Notch-mediated lateral specification, which ensures that only one AC forms (Greenwald et al. 1983). The AC expresses LIN-3/ EGF (the "inductive signal") to stimulate LET-23/EGFR and the Ras pathway in the nearest VPC (P6.p) (Hill and Sternberg 1992). Ras promotes the $1^{\circ}$ fate (Beitel et al. 1990; Han et al. 1990; Simske and Kim 1995). That $1^{\circ}$ VPC then expresses multiple DSL ligands (the "lateral signal") to stimulate LIN-12/Notch in the two flanking VPCs (P5.p and P7.p) (Chen and Greenwald 2004). LIN-12/Notch promotes the $2^{\circ}$ fate (Greenwald et al. 1983). Distal VPCs in which both Ras and Notch activity are low adopt the $3^{\circ}$ fate. Within a given VPC, the Ras and Notch pathways antagonize each other such that only one of the two pathways is highly active (Fig. 3B; Berset et al. 2001; Shaye and Greenwald 2002; Yoo et al. 2004).

\section{C. elegans Ras or Notch targets important for vulval fates}

let-23/EGFR and let-60/Ras are required cell autonomously for the $1^{\circ}$ vulval fate of P6.p (Simske and Kim 1995; Yochem et al. 1997), but precisely how Ras signaling promotes this fate is still poorly understood. The best understood ERK target, the Ets domain protein LIN-1, is not required for the $1^{\circ}$ fate; instead, LIN-1 seems to act primarily as a repressor of the $1^{\circ}$ fate, and ERK phosphorylation prevents this (Beitel et al. 1995; Jacobs et al. 1998). However, the Mediator component SUR-2 does promote the $1^{\circ}$ vulval fate (Singh and Han 1995), suggesting that LIN-1 could have a SUR-2-dependent activator function that becomes irrelevant in the absence of its repressor function (Howard and Sundaram 2002). Alternatively, SUR-2 could act with other, unknown, transcription factors.

Additional nuclear factors that help specify the $1^{\circ}$ fate include several widely expressed proteins (Tuck and Greenwald 1995; Howard and Sundaram 2002) and several transcription factors with relatively restricted expression patterns (Miller et al. 1993; Maloof and Kenyon 1998; Grant et al. 2000; Koh et al. 2002). Of these, only the forkhead-related transcription factor LIN-31 has been shown to be phosphorylated by ERK; this phosphorylation converts LIN-31 from a transcriptional repressor to an activator (Tan et al. 1998). Ras signaling increases expression levels of the Hox protein LIN-39, suggesting that LIN-39 could be a transcriptional target of the Ras pathway (Maloof and Kenyon 1998). Ectopic expression of LIN-31 or LIN-39 can cause other tissues to adopt vulval-like characteristics in response to Ras signaling, suggesting that the presence of these transcription factors may be important contextual features that determine vulva-specific responses to Ras signaling (Maloof and Kenyon 1998; Tan et al. 1998).

LIN-12/Notch specifies the $2^{\circ}$ vulval fate in P5.p and P7.p, but again, how it promotes the $2^{\circ}$ fate is poorly understood. LIN-12 acts through the CSL transcription factor LAG-1 to drive transcription of various "lateral signal target" (1st) genes in the $2^{\circ}$ VPCs P5.p and P7.p 
(Berset et al. 2001; Yoo et al. 2004). Among the 1st gene set are presumably genes that help specify the $2^{\circ}$ fate, but the key genes involved are unknown. The best characterized lst genes are inhibitors of Ras pathway activity (see below).

\section{Drosophila eye development}

The Drosophila eye also has been a very powerful system for studying Ras and Notch signaling (Voas and Rebay 2004). The eye is made up of $\sim 800$ identical units called ommatidia, each of which forms from just 19 precursor cells. Eight of these precursors become photoreceptor neurons of distinct subtypes (R1-R8), four become nonneuronal lens-secreting cone cells, and the rest become nonneuronal pigment and bristle cells (Fig. 4). Both Ras and Notch control numerous aspects of eye development, and this topic has been reviewed extensively (Brennan and Moses 2000; Frankfort and Mardon 2002; Voas and Rebay 2004). Here I focus on just a few specific roles of Ras and Notch to highlight the similarities and differences regarding the C. elegans vulval system.

The R8 photoreceptor is the first cell to differentiate within an ommatidium and functions as an organizer cell to recruit and pattern the remaining precursors (Tomlinson and Ready 1987). R8 formation is inhibited by Notch-mediated lateral inhibition, which ensures that only a limited number and regularly spaced set of R8 cells will form (Cagan and Ready 1989; Baker and Zitron 1995). R8 expresses the ligand Spitz/EGF to stimulate EGFR and the Ras pathway in nearby precursor cells (Freeman 1994; Tio et al. 1994). Ras induces these cells to join the R8 precluster and differentiate as additional photoreceptors (R cells) (Freeman 1996; Dominguez et al. 1998; Kumar et al. 1998; Yang and Baker 2001). Ras also promotes expression of the Notch ligand Delta within those R cells (Tsuda et al. 2002), and Ras and Notch then cooperate to promote additional R-cell fates (e.g., the R7 fate) and cone cell fates (Fig. 4; Cooper and Bray 2000; Tomlinson and Struhl 2001; Tsuda et al. 2002). This system differs from C. elegans vulval development in that some cell types require direct inputs from both Ras and Notch. Furthermore, temporal differences (independent of spatial differences) often determine the specific fate adopted.

Another important distinction between C. elegans and Drosophila is that Ras and Notch have no apparent roles in cell growth, survival, or proliferation of vulval cells (Yochem et al. 1997) (although Ras and Notch do control germline proliferation and meiosis (Austin and Kimble 1987; Church et al. 1995). In contrast, the Ras pathway is required for growth and survival of most cells in the fly eye (Simon et al. 1991; Xu and Rubin 1993; Prober and Edgar 2000; Halfar et al. 2001). Furthermore, in a specific subset of eye precursor cells that participate in what is termed the "second mitotic wave" (SMW), Notch is required for G1-to-S progression while EGFR and Ras are required for G2-to-M progression (Baker and Yu 2001; Baonza et al. 2002; Baonza and Freeman 2005; Firth and Baker 2005). These developmentally restricted roles of
Ras and Notch in cell cycle progression further highlight how context determines the responses to signaling.

\section{Drosophila Ras and/or Notch targets important for photoreceptor or cone cell fates}

Both Ras and Notch act cell autonomously to specify multiple fates in the Drosophila eye. Combinatorial models have been proposed to explain how Ras (acting through the Ets factors Yan and Pointed) and Notch [acting through the CSL factor $\mathrm{Su}(\mathrm{H})$ ] can elicit different fates in different eye precursor cells. For example, all cells entering and arising from the SMW express the Runt-like transcription factor lozenge, which is required for R1, R6, R7, and cone cell fates (Daga et al. 1996; Flores et al. 1998). The combination of lozenge plus high EGFR activity drives expression of the homeodomain transcription factor Bar to specify the R1 and R6 fates (Higashijima et al. 1992; Daga et al. 1996). The combination of lozenge plus high EGFR and high Sevenless RTK activity drives expression of the homeodomain transcription factor Prospero to help specify the R7 fate (Xu et al. 2000). Also, Notch represses Bar expression in R7 to prevent R7 from adopting R1/R6 characteristics (Cooper and Bray 2000; Tomlinson and Struhl 2001). The combination of lozenge plus high EGFR and high Notch drives expression of the paired box transcription factor D-Pax-2 to specify the cone cell fate (Flores et al. 2000). Because both R7 and cone cells possess lozenge, active EGFR, and active Notch, these models also postulate that different levels and/or different timing of Ras and Notch activation can affect fate choice.

An important negative target of the Ras pathway in R1, R6, and R7 (but not cone cells) is the BTB/Zinc finger domain protein Tramtrack (Ttk). Ttk is a repressor of photoreceptor fates (Xiong and Montell 1993). Ras downregulates Ttk in R1, R6, and R7 by stimulating expression of the E3 component phyllopod (Chang et al. 1995; Dickson et al. 1995). Phyllopod, the F-box protein Ebi, and the RING-finger protein Sina then act together to target Ttk for ubiquitin-mediated proteolysis (Li et al. 1997, 2002; Tang et al. 1997; Dong et al. 1999). It is not clear how Ras stimulates Phyllopod expression, or what factors limit this effect to R1, R6, and R7.

\section{Sequential Ras and Notch signaling in adjacent cells}

Studies of vulval development and eye development have revealed different kinds of relationships between Ras and Notch in different cell types. Despite this variability, some common themes can be recognized (Fig. 5). The first is that activation of Ras or Notch in one cell can influence ligand expression to affect signaling in adjacent cells. Notch tends to negatively influence EGF expression, while Ras tends to positively influence DSL ligand expression.

\section{Notch inhibits EGF expression or activity}

By inhibiting AC formation in C. elegans and R8 formation in Drosophila, Notch negatively influences EGF 

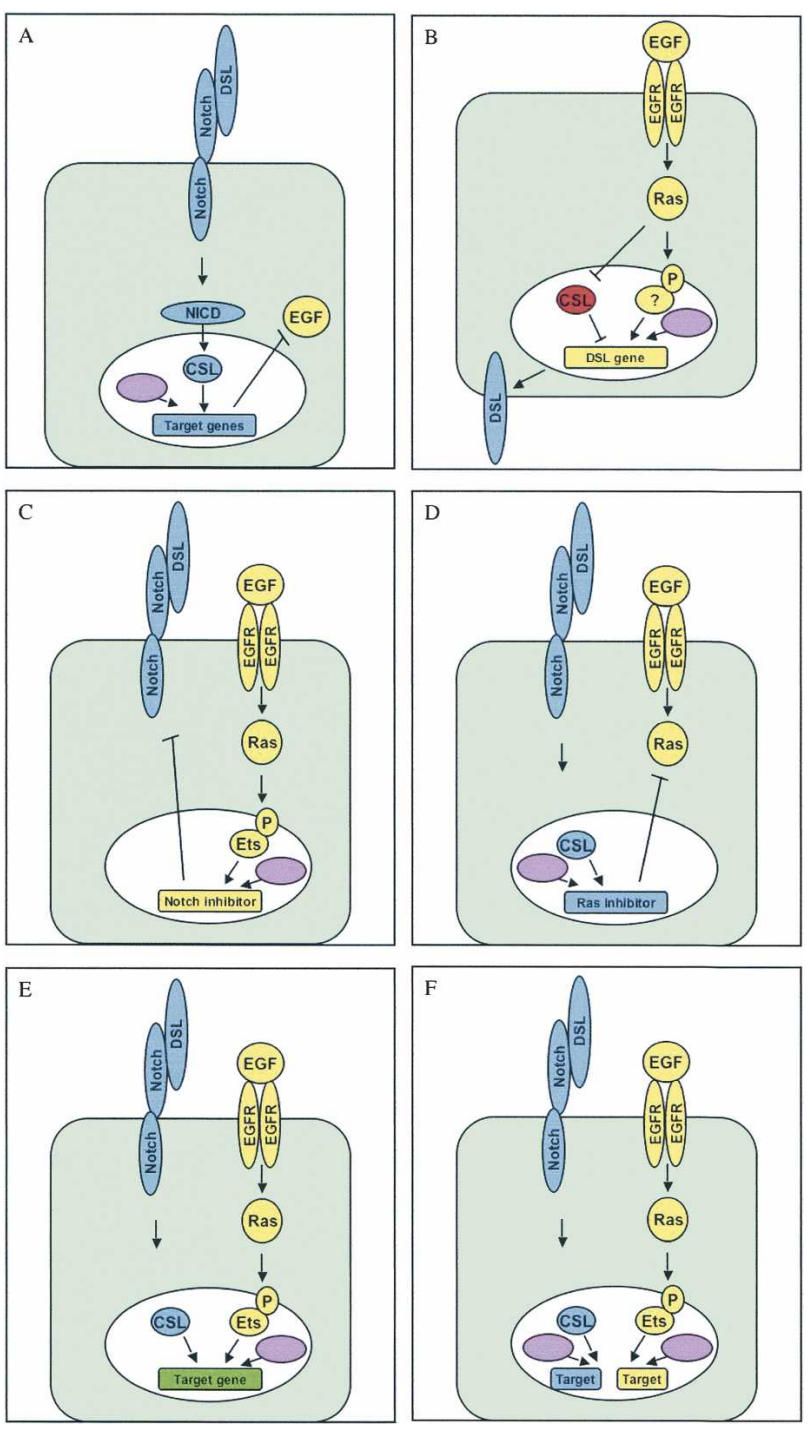

Figure 5. Mechanisms of sequential, antagonistic, and cooperative interactions between Ras and Notch. Ras pathway components are shown in yellow, Notch pathway components are shown in blue, and contextual factors are shown in purple. $(A)$ Sequential signaling: Notch prevents expression of active EGF in the anchor cell of C. elegans and the R8 cell of Drosophila, spatially limiting the extent of Ras activation. $(B)$ Sequential signaling: Ras induces the transcription of DSL ligand genes in the P6.p cell of C. elegans and in multiple R cells of Drosophila. (C) Antagonism: Ras induces the transcription of Notch inhibitors in the P6.p cell of C. elegans. (D) Antagonism: Notch induces the transcription of Ras inhibitors in the P5.p and P7.p cells of C. elegans and in undifferentiated eye cells of Drosophila. (E) Cooperation: Ras- and Notch-stimulated transcription factors converge on a common promoter in cone cells of Drosophila. $(F)$ Cooperation or sequential action within a cell: Ras- and Notch-stimulated transcription factors may act on distinct promoters in the R7 cell and in eye cells undergoing the SMW in Drosophila. See text for details and references.

production to limit Ras pathway activation in surrounding cells (Fig. 5A).

In C. elegans, lin-3/EGF expression is restricted to the
AC by transcriptional mechanisms. The bHLH transcription factor HLH-2 is an important activator of lin3/EGF transcription (Hwang and Sternberg 2004), and LIN-12/Notch signaling leads to post-transcriptional down-regulation of HLH-2 in the cell that does not become the AC (Karp and Greenwald 2003). Thus LIN-12/ Notch signaling limits lin-3/EGF transcription.

In Drosophila, Spitz/EGF expression is fairly ubiquitous within the eye, but Spitz activity requires proteolytic processing by Star and Rhomboid (Wasserman et al. 2000; Tsruya et al. 2002; Urban et al. 2002). The bHLH transcription factor Atonal is an important activator of Rhomboid transcription (Baonza et al. 2001), and Notch signaling represses Atonal expression outside of R8 (Baker et al. 1996; Ligoxygakis et al. 1998). Thus Notch signaling limits the production of processed, active Spitz/EGF.

\section{Ras promotes expression of DSL ligands}

In the P6.p cell of the C. elegans vulva and in the R cells of the Drosophila eye, Ras activation leads to expression of DSL ligand(s) that can activate Notch in surrounding cells (Fig. 5B). In both cases, DSL expression is controlled at the level of transcription, although the specific mechanisms may vary. The spatial and temporal linkage of Ras signaling and DSL expression ensures that Notchdependent cell fates are generated adjacent to and subsequent to Ras-dependent cell types.

In C. elegans, Ras activation in P6.p stimulates the transcription of three redundantly acting DSL genes, apx-1, dsl-1, and lag-2 (Chen and Greenwald 2004). lag-2 is actually expressed at low levels in all VPCs independently of Ras, but Ras signaling specifically up-regulates its expression in P6.p. The Ras-dependent increases in DSL gene expression require the Mediator component SUR-2 (Chen and Greenwald 2004), suggesting that the DSL genes might be positive transcriptional targets of the Ets protein LIN-1 or of some other Ras-regulated transcription factor.

In Drosophila, Ras activation in $\mathrm{R}$ cells stimulates Delta expression by antagonizing the repressor function of the CSL transcription factor Suppressor of Hairless $[\mathrm{Su}(\mathrm{H})]$ (Tsuda et al. 2002). Su(H) normally represses Delta transcription [this is a Notch-independent function for $\mathrm{Su}(\mathrm{H})]$. Derepression of Delta involves the F-box protein Ebi and the novel nuclear protein Strawberry Notch (Sno), which cause the corepressor protein SMRTER to dissociate from $\mathrm{Su}(\mathrm{H})$ and translocate out of the nucleus. Although the details of this mechanism remain to be worked out, one hypothesis is that Ras signaling causes Ebi and Sno-dependent proteosomal degradation of one or more components of a $\mathrm{Su}(\mathrm{H})$-SMRTER repressor complex (Tsuda et al. 2002). Whether Ras acts through the Ets protein Pointed or through some other ERK target is unknown.

\section{Sequential Ras and Notch signaling within a cell}

Ras and Notch may act at different times within the same cell to control different aspects of a cell's fate. For 
example, recent studies in the Drosophila eye show that Ras and Notch act cell autonomously to promote different steps of cell cycle progression during the SMW.

The SMW is a synchronous round of mitosis that separates the early and later phases of photoreceptor fate specification (Fig. 4). Prior to R8 specification, eye precursor cells arrest in the G1 phase of the cell cycle. The early photoreceptors R8 and R2-R5 remain arrested in G1 and differentiate, but surrounding undifferentiated cells proceed into a single round of mitosis to generate more precursor cells that will eventually differentiate as R1, R6, R7, or nonneuronal cells of the ommatidium.

Delta and Notch are required for G1-to-S progression in the SMW (Baonza and Freeman 2005; Firth and Baker 2005). Notch appears to act through $\mathrm{Su}(\mathrm{H})$ to down-regulate RBF1 activity, thereby increasing E2F activity to drive S-phase entry. Notch also up-regulates Cyclin A expression. S-phase entry occurs only in cells with low EGFR activity (i.e. not in R2-R5), suggesting that EGFR antagonizes the S-phase-promoting activity of Notch. The mechanism of this antagonism is not known, but it effectively limits the SMW to those cells that experience Notch activation prior to strong EGFR activation.

Low levels of EGFR (and presumably Ras) are required for G2-to-M progression in the SMW (Baker and Yu 2001). EGFR signals through the Ets factor Pointed and the BTB/Zinc finger domain protein Ttk to up-regulate expression of the cdc25 phosphatase STRING, thereby driving mitotic entry (Baonza et al. 2002). Although the relationship between EGFR and Notch has not been tested directly, presumably EGFR can only drive mitotic entry of cells that have previously experienced Notch signaling, are in G2, and therefore are competent to respond to STRING.

\section{Antagonism of Ras and Notch within a cell}

When both Ras and Notch become activated in the same cell, the two pathways frequently antagonize each other (zur Lage and Jarman 1999; Berset et al. 2001; Culi et al. 2001; Carmena et al. 2002; Rohrbaugh et al. 2002; Shaye and Greenwald 2002; Yoo et al. 2004; Hasson et al. 2005). This occurs because each pathway can affect the expression levels or activities of various components or regulators of the other pathway (Fig. 5C,D). The relative strength and timing of Ras versus Notch signaling appears to determine which pathway "wins" the battle for prominence.

\section{Ras down-regulates Notch expression}

In C. elegans, AC-produced LIN-3/EGF strongly activates the Ras pathway in P6.p (where it is required), and more weakly activates the Ras pathway in P5.p and P7.p (where it is not required) (Simske and Kim 1995; Yochem et al. 1997; Yoo et al. 2004). Strong Ras signaling in P6.p down-regulates LIN-12/Notch protein levels, whereas weaker Ras signaling in P5.p and P7.p does not have this effect (Fig. 3B; Levitan and Greenwald 1998).
Ras down-regulates LIN-12 through a mechanism that involves LIN-12 endocytosis (Shaye and Greenwald 2002). Initially, LIN-12 is expressed in all six VPCs, but at the time of Ras signaling, LIN-12 protein levels decrease in P6.p and the remaining LIN-12 is detected in intracellular puncta. This effect requires a di-leucine endocytic sorting motif in the LIN-12 intracellular domain. This effect also requires SUR-2, suggesting that it involves Ras-dependent transcriptional changes. Thus Ras may stimulate the transcription of unknown factors involved in LIN-12 endocytosis.

Interestingly, Ras-mediated down-regulation of LIN12/Notch in P6.p is critical for successful LIN-12/Notch signaling in adjacent cells (Shaye and Greenwald 2002). Expression of a persistent form of LIN-12 in P6.p has no apparent effect on $1^{\circ}$ fate specification in P6.p, but interferes with $2^{\circ}$ fate specification in P5.p and P7.p. Therefore, down-regulation of LIN-12 in P6.p may be important for the expression or activity of DSL ligands that comprise the lateral signal. (Note that such a requirement could explain why Ras-independent expression of the lag-2 DSL gene in VPCs is not sufficient to activate LIN-12/Notch.) It appears that the observed molecular antagonism between Ras and Notch is really another aspect of sequential signaling.

Although persistent LIN-12 expression in P6.p is not deleterious for $1^{\circ}$ fate specification, high LIN-12 activity can convert P6.p to a $2^{\circ}$ fate (Greenwald et al. 1983; Sternberg 1988; Sternberg and Horvitz 1989|. By coupling DSL up-regulation to LIN-12 down-regulation, the Ras pathway would ensure that LIN-12 never has a chance to become highly active in P6.p.

\section{Ras blocks the transcriptional activity of Notch targets}

Recent studies in other systems indicate that EGFR/Ras signaling can also interfere with Notch signaling at points further downstream. In the Drosophila wing, MAPK phosphorylates Groucho (Gro), weakening its ability to function as a corepressor for the $\mathrm{E}(\mathrm{spl})$ proteins (Hasson et al. 2005). Ras-dependent attenuation of Groucho would effectively block E(spl)-dependent Notch responses, while potentially leaving other, E(spl)-independent Notch responses intact. However, since Groucho also functions as a corepressor for numerous other transcription factors [including $\mathrm{Su}(\mathrm{H})$ ], Ras-dependent attenuation of Groucho could have quite widespread effects. In zebrafish somites, fibroblast growth factor (FGF), which acts in part through Ras, stimulates expression of a specific HES factor that then represses expression of other Notch-induced HES factors (Kawamura et al. 2005). This mechanism may be a more specific way to interfere with Notch responses.

Notch stimulates transcription of Ras pathway inhibitors

One way that Notch antagonizes Ras is by driving the transcription of genes that directly inhibit Ras signaling 
(Fig. 5D). These effects require Notch-stimulated CSL factors, but presumably also require other (unknown) cooperating transcription factors, explaining why antagonism occurs in some cells but not others.

In C. elegans, LIN-12/Notch acts through the CSL transcription factor LAG-1 to drive transcription of numerous 1st genes in P5.p and P7.p (Yoo et al. 2004). Many 1st genes encode inhibitors of the Ras pathway. For example, 1st gene products include the ERK phosphatase LIP-1 (Berset et al. 2001), the EGFR inhibitor ARK-1 (Hopper et al. 2000), and various proteins involved in EGFR endocytosis and degradation (Yoo et al. 2004). Blocking expression of just one such lst gene leads to increased Ras activity in P5.p and P7.p as judged by increased expression of a Ras-responsive reporter; however, it has no phenotypic effect. Blocking expression of multiple 1st genes at once can cause a multivulva phenotype similar to that caused by constitutive Ras. Although low levels of Ras signaling in P5.p and P7.p are apparently not a problem, and may even cooperate with LIN-12/Notch (Katz et al. 1995), high levels of Ras signaling are incompatible with the $2^{\circ}$ fate (Sternberg and Horvitz 1989|. LIN-12/Notch-mediated up-regulation of multiple Ras inhibitors ensures that Ras signaling is kept in check (Fig. 3B).

Several other inhibitors of the Ras pathway are expressed in VPCs independently of LIN-12/Notch signaling. For example, the microRNA mir-84 negatively regulates LET-60/Ras expression (Johnson et al. 2005), and the tyrosine phosphatase DEP-1 negatively regulates LET-23/EGFR activity (Berset et al. 2005). Both mir-84 and $d e p-1$ are initially expressed in all six VPCs but are down-regulated in P6.p (or its daughters) in response to Ras activation. mir-84 and dep-1 remain expressed in P5.p and P7.p and cooperate with the Notch-regulated 1st genes to keep Ras activity low in those cells.

In Drosophila, Notch acts through the CSL transcription factor $\mathrm{Su}(\mathrm{H})$ to promote transcription of the Ets domain repressor Yan in undifferentiated precursor cells of the eye (Rohrbaugh et al. 2002). Yan may be important to prevent premature differentiation in the presence of low EGFR activity, and instead restrict differentiation to cells that receive higher levels of EGF. The ability of Notch to up-regulate Yan may explain some cases where constitutive Notch seems to maintain the undifferentiated state (Cagan and Ready 1989; Voas and Rebay 2004).

\section{Cooperation of Ras and Notch within a cell}

Ras and Notch do not always act in opposition. In some circumstances, Ras and Notch can cooperate within a cell to specify a particular cell fate (Katz et al. 1995; Cooper and Bray 2000; Flores et al. 2000; Tomlinson and Struhl 2001). Furthermore, in Drosophila either activated Ras or Notch can cooperate with the polarity mutant scribble to promote neoplastic growth, suggesting that the two pathways are to some degree interchangeable (Brumby and Richardson 2003). Ras and Notch may cooperate directly by up-regulating a common target gene (Fig. 5E), or indirectly, by acting on different targets that each contribute toward a common fate (Fig. 5F).

Ras- and Notch-stimulated Ets and CSL transcription factors converge on a common promoter to activate gene expression

Both Ras and Notch are required cell autonomously for the Drosophila cone cell fate, and cooperate directly to up-regulate the paired-box transcription factor D-Pax 2 in cone cells (Flores et al. 2000). D-Pax2 is required for the cone cell fate, and is specifically expressed in cone cells but not R cells (Fu and Noll 1997). The Runt-like transcription factor lozenge, the Ras-stimulated Ets factor Pointed, and the Notch-stimulated CSL factor $\mathrm{Su}(\mathrm{H})$ each bind to elements in the D-Pax 2 promoter and cooperatively drive its transcription in cone cells. Mutation of either the Pointed or $\mathrm{Su}(\mathrm{H})$-binding sites prevents D-Pax2 transcription, showing that both the Ras and Notch pathways are required directly for promoter activity. In this case the presence of lozenge is a key contextual factor allowing Ras and Notch cooperation.

Ras and Notch-stimulated Ets and CSL transcription factors may act on distinct promoters to promote a common fate

Ras and Notch also cooperate to promote the Drosophila R7 photoreceptor fate (Fig. 4B; Cooper and Bray 2000; Tomlinson and Struhl 2001). The mechanism of cooperation is less clear here, but may involve distinct targets of the two pathways.

Two different RTKs_EGFR and Sevenless (Sev)—are both required for the high levels of Ras signaling needed to distinguish R7 from cone cells (Freeman 1996). When Ras signaling is reduced in the $\mathrm{R} 7$ precursor, that cell instead adopts a cone cell fate (Simon et al. 1991). Prospero is one transcription factor that is highly expressed in R7 but more weakly expressed in cone cells. Studies of Prospero reporter constructs suggest that EGFR and Ras signal through the Ets factor Pointed to promote early Prospero transcription, while Sev and Ras act slightly later to down-regulate the BTB/Zinc finger repressor Ttk and further stimulate Prospero transcription to high levels (Xu et al. 2000). An important conclusion of these studies is that inducing the R7 fate takes time.

Notch signaling is needed to distinguish R7 from R1/ R6; when Notch signaling is reduced in the R7 precursor, that cell instead adopts an R1/R6 fate (Cooper and Bray 2000; Tomlinson and Struhl 2001). Notch signals through $\mathrm{Su}(\mathrm{H})$ and the $\mathrm{Su}(\mathrm{H})$ target gene E(spl)M $\delta$ (a transcriptional repressor) to prevent expression of the transcription factor Bar in R7. This role of Notch is seemingly distinct from that of the Ras pathway, which normally promotes Bar expression in R1/R6 (Daga et al. 1996). These observations suggest that Notch may actually prevent Ras from inducing Bar expression early, thereby allowing stronger, more sustained Ras signaling to induce prospero and other genes needed for the alter- 
native R7 fate (Cooper and Bray 2000). Such a model, if true, would add an extra twist to the idea of cooperation versus antagonism: Notch may antagonize Ras only at certain times or only at specific promoters in order to focus the effects of Ras signaling on other promoters.

\section{All is fair in love and war}

These studies in worms and flies reveal the importance of combinatorial interactions, signaling intensity, and relative timing in determining the outcomes of Ras and Notch signaling. However, they do not leave us with any clear "rules" that can predict what those outcomes will be, or when Ras and Notch will cooperate and when they will battle. Perhaps each cell type presents its own unique context and must be studied as an individual case. Or perhaps we just need more data before the universal rules become apparent. Despite our still incomplete understanding of even these simple systems, the worm vulva and fly eye provide some general paradigms for the types of Ras-Notch interactions we can expect to see in more complex organisms such as mammals.

\section{Ras and Notch in mammalian tumorigenesis}

In mammals, interactions between Ras and Notch may be particularly important for determining whether and how alterations in Ras and Notch lead to cancer. ras is well known as an oncogene; activating mutations in ras are very frequent in human cancers and can promote a wide variety of tumors in mice (Malumbres and Barbacid 2002). Yet in certain tissues, ras appears to function as a tumor suppressor (Zhang et al. 2001; James et al. 2003; Diaz et al. 2004). Notch can also function as an oncogene or tumor suppressor, depending on the tissue (Radtke and Raj 2003; Fan et al. 2004; Lefort and Dotto 2004). Activating mutations in Notch1 are a frequent cause of T-cell acute lymphoblastic leukemia (T-ALL) in humans (Ellisen et al. 1991; Weng et al. 2004), and activated versions of multiple Notch paralogs can promote T-cell, mammary, and salivary gland tumors in mice (Jhappan et al. 1992; Pear et al. 1996; Gallahan and Callahan 1997; Dievart et al. 1999; Bellavia et al. 2000; Kiaris et al. 2004). Yet in skin, Notch1 inhibits cell proliferation and promotes differentiation of keratinocytes, and Notch1 ${ }^{-/-}$ mice develop basal skin carcinomas (Rangarajan et al. 2001; Nicolas et al. 2003; Okuyama et al. 2004). As in worms and flies, the specific consequences of Ras or Notch signaling appear highly context-dependent, and may depend in part on interactions between the two pathways.

Several studies suggest that the ability of activated Ras or Notch to transform cells depends on cooperation with the other (Dievart et al. 1999; Fitzgerald et al. 2000; Haruki et al. 2005), and the mechanisms of cooperation may be similar to those described above. For example, in human cultured cells transformed by a combination of active Ras, SV40, and hTERT, Ras acts through p38 MAP kinase to up-regulate expression of Delta1 and Notch1
(Weijzen et al. 2002). Interfering with Notch signaling in this system inhibits anchorage-independent growth, suggesting that sequential signaling through Notch (e.g., Fig. 5B) is critical for Ras-induced transformation. Similarly, in mice, overexpression of the Notch inhibitor Deltex1 inhibits Hras1-induced mammary tumorigenesis (Kiaris et al. 2004). In this mouse mammary tumor model, both Hras1 and Notch1 up-regulate expression of cyclinD1, suggesting that the mode of cooperation might be convergent up-regulation of a common target (Fig. 5E).

On the other hand, Ras and Notch may also antagonize each other during tumorigenesis. For example, in NIH3T3 cells, reducing Notch activity facilitates transformation by Fgf (which acts in part through Ras), and Notch and Fgf both inhibit each other's expression (Small et al. 2003). Thus in this context, Notch appears to function like a tumor suppressor.

Unraveling Ras-Notch relationships in mammals will be complicated. For example, mammals have three Ras genes (K-Ras, H-Ras, and N-Ras) that can signal through multiple Raf genes as well as through alternative downstream targets such as PI3-kinase, Ral-GDS, and RASSF (Repasky et al. 2004). Mammals also have four Notch genes (Notch1-4) (Radtke and Raj 2003). The diversification of Ras and Notch family members may allow individual isoforms to experience unique modes of regulation or to signal through unique targets $\left(\mathrm{O}^{\prime} \mathrm{Neill}\right.$ and Kolch 2004; Rodriguez-Viciana et al. 2004). The use of alternative pathways will further amplify the numbers and types of potential responses and mechanisms of cross-talk. Despite the challenges, the motivation for understanding Ras and Notch in mammals is strong because of the huge importance of these pathways in human disease and cancers.

\section{Acknowledgments}

I apologize to all those whose work was inadequately cited. Thanks to Brian Calvi, Tom Kadesch, Mark Fortini, Spyros Artavanis-Tsakonas, Paul Sternberg, John Yochem, Iva Greenwald, and Min Han for recent and historical discussions about Ras and Notch. Research in my laboratory is supported by NIH grants GM58540 and CA87512.

\section{References}

Artavanis-Tsakonas, S., Rand, M.D., and Lake, R.J. 1999. Notch signaling: Cell fate control and signal integration in development. Science 284: 770-776.

Austin, J. and Kimble, J. 1987. glp-1 is required in the germline for regulation of the decision beetween mitosis and meiosis in C. elegans. Cell 51: 589-599.

Bailey, A.M. and Posakony, J.W. 1995. Suppressor of hairless directly activates transcription of enhancer of split complex genes in response to Notch receptor activity. Genes \& Dev. 9: 2609-2622.

Baker, N.E. and Yu, S.Y. 2001. The EGF receptor defines domains of cell cycle progression and survival to regulate cell number in the developing Drosophila eye. Cell 104: 699708.

Baker, N.E. and Zitron, A.E. 1995. Drosophila eye development: 
Notch and Delta amplify a neurogenic pattern conferred on the morphogenetic furrow by scabrous. Mech. Dev. 49: 173189.

Baker, N.E., Yu, S., and Han, D. 1996. Evolution of proneural atonal expression during distinct regulatory phases in the developing Drosophila eye. Curr. Biol. 6: 1290-1301.

Baker, D.A., Mille-Baker, B., Wainwright, S.M., Ish-Horowicz, D., and Dibb, N.J. 2001. Mae mediates MAP kinase phosphorylation of Ets transcription factors in Drosophila. Nature 411: 330-334.

Baonza, A. and Freeman, M. 2005. Control of cell proliferation in the Drosophila eye by Notch signaling. Dev. Cell 8: 529539.

Baonza, A., Casci, T., and Freeman, M. 2001. A primary role for the epidermal growth factor receptor in ommatidial spacing in the Drosophila eye. Curr. Biol. 11: 396-404.

Baonza, A., Murawsky, C.M., Travers, A.A., and Freeman, M. 2002. Pointed and Tramtrack69 establish an EGFR-dependent transcriptional switch to regulate mitosis. Nat. Cell Biol. 4: 976-980.

Barolo, S. and Posakony, J.W. 2002. Three habits of highly effective signaling pathways: Principles of transcriptional control by developmental cell signaling. Genes \& Dev. 16: 1167-1181.

Beitel, G.J., Clark, S.G., and Horvitz, H.R. 1990. Caenorhabditis elegans ras gene let-60 acts as a switch in the pathway of vulval induction. Nature 348: 503-509.

Beitel, G.J., Tuck, S., Greenwald, I., and Horvitz, H.R. 1995. The Caenorhabditis elegans gene lin-1 encodes an ETS-domain protein and defines a branch in the vulval induction pathway. Genes \& Dev. 9: 3149-3162.

Bellavia, D., Campese, A.F., Alesse, E., Vacca, A., Felli, M.P., Balestri, A., Stoppacciaro, A., Tiveron, C., Tatangelo, L., Giovarelli, M., et al. 2000. Constitutive activation of NF-кB and T-cell leukemia/lymphoma in Notch3 transgenic mice. EMBO I. 19: 3337-3348.

Berset, T., Hoier, E.F., Battu, G., Canevascini, S., and Hajnal, A. 2001. Notch inhibition of RAS signaling through MAP kinase phosphatase LIP-1 during C. elegans vulval development. Science 291: 1055-1058.

Berset, T.A., Frohli Hoier, E., and Hajnal, A. 2005. The C. elegans homolog of the tumor suppressor Dep-1/Scc1 inhibits EGFR signaling to regulate binary fate decisions. Genes \& Dev. 19: 1328-1340.

Brennan, C.A. and Moses, K. 2000. Determination of Drosophila photoreceptors: Timing is everything. Cell. Mol. Life Sci. 57: 195-214.

Brumby, A.M. and Richardson, H.E. 2003. scribble mutants cooperate with oncogenic Ras or Notch to cause neoplastic overgrowth in Drosophila. EMBO J. 22: 5769-5779.

Brunner, D., Ducker, K., Oellers, N., Hafen, E., Scholz, H., and Klambt, C. 1994. The ETS domain protein pointed-P2 is a target of MAP kinase in the sevenless signal transduction pathway. Nature 370: 386-389.

Bumeister, R., Rosse, C., Anselmo, A., Camonis, J., and White, M.A. 2004. CNK2 couples NGF signal propagation to multiple regulatory cascades driving cell differentiation. Curr. Biol. 14: 439-445.

Cagan, R.L. and Ready, D.F. 1989. Notch is required for successive cell decisions in the developing Drosophila retina. Genes \& Dev. 3: 1099-1112.

Carmena, A., Buff, E., Halfon, M.S., Gisselbrecht, S., Jimenez, F., Baylies, M.K., and Michelson, A.M. 2002. Reciprocal regulatory interactions between the Notch and Ras signaling pathways in the Drosophila embryonic mesoderm. Dev. Biol. 244: 226-242.
Casci, T., Vinos, J., and Freeman, M. 1999. Sprouty, an intracellular inhibitor of Ras signaling. Cell 96: 655-665.

Cave, J.W., Loh, F., Surpris, J.W., Xia, L., and Caudy, M.A. 2005. A DNA transcription code for cell-specific gene activation by notch signaling. Curr. Biol. 15: 94-104.

Chang, H.C., Solomon, N.M., Wassarman, D.A., Karim, F.D., Therrien, M., Rubin, G.M., and Wolff, T. 1995. phyllopod functions in the fate determination of a subset of photoreceptors in Drosophila. Cell 80: 463-472.

Chen, N. and Greenwald, I. 2004. The lateral signal for LIN-12/ Notch in C. elegans vulval development comprises redundant secreted and transmembrane DSL proteins. Dev. Cell 6: 183-192.

Chen, G., Fernandez, J., Mische, S., and Courey, A.J. 1999. A functional interaction between the histone deacetylase Rpd3 and the corepressor groucho in Drosophila development. Genes \& Dev. 13: 2218-2230.

Church, D.L., Guan, K.-L., and Lambie, E.J. 1995. Three genes of the MAP kinase cascade, mek-2, mpk-1/sur-1, and let-60 ras are required for meiotic cell cycle progression in Caenorhabditis elegans. Development 121: 2525-2535.

Cooper, M.T. and Bray, S.J. 2000. R7 photoreceptor specification requires Notch activity. Curr. Biol. 10: 1507-1510.

Cooper, M.T., Tyler, D.M., Furriols, M., Chalkiadaki, A., Delidakis, C., and Bray, S. 2000. Spatially restricted factors cooperate with notch in the regulation of Enhancer of split genes. Dev. Biol. 221: 390-403.

Cox, A.D. and Der, C.J. 2003. The dark side of Ras: Regulation of apoptosis. Oncogene 22: 8999-9006.

Culi, J., Martin-Blanco, E., and Modolell, J. 2001. The EGF receptor and $\mathrm{N}$ signalling pathways act antagonistically in Drosophila mesothorax bristle patterning. Development 128: 299-308.

Daga, A., Karlovich, C.A., Dumstrei, K., and Banerjee, U. 1996. Patterning of cells in the Drosophila eye by Lozenge, which shares homologous domains with AML1. Genes \& Dev. 10: 1194-1205.

Deftos, M.L., He, Y.W., Ojala, E.W., and Bevan, M.J. 1998. Correlating notch signaling with thymocyte maturation. Immunity 9: 777-786.

Diaz, R., Lopez-Barcons, L., Ahn, D., Garcia-Espana, A., Yoon, A., Matthews, J., Mangues, R., Perez-Soler, R., and Pellicer, A. 2004. Complex effects of Ras proto-oncogenes in tumorigenesis. Carcinogenesis 25: 535-539.

Dickson, B.J., Dominguez, M., van der Straten, A., and Hafen, E. 1995. Control of Drosophila photoreceptor cell fates by phyllopod, a novel nuclear protein acting downstream of the Raf kinase. Cell 80: 453-462.

Dievart, A., Beaulieu, N., and Jolicoeur, P. 1999. Involvement of Notch 1 in the development of mouse mammary tumors. Oncogene 18: 5973-5981.

Dominguez, M., Wasserman, J.D., and Freeman, M. 1998. Multiple functions of the EGF receptor in Drosophila eye development. Curr. Biol. 8: 1039-1048.

Dong, X., Tsuda, L., Zavitz, K.H., Lin, M., Li, S., Carthew, R.W., and Zipursky, S.L. 1999. ebi regulates epidermal growth factor receptor signaling pathways in Drosophila. Genes \& Dev. 13: 954-965.

Doyle, T.G., Wen, C., and Greenwald, I. 2000. SEL-8, a nuclear protein required for LIN-12 and GLP-1 signaling in Caenorhabditis elegans. Proc. Nat1. Acad. Sci. 97: 7877-7881.

Ellisen, L.W., Bird, J., West, D.C., Soreng, A.L., Reynolds, T.C., Smith, S.D., and Sklar, J. 1991. TAN-1, the human homolog of the Drosophila notch gene, is broken by chromosomal translocations in T lymphoblastic neoplasms. Cell 66: 649661 . 
Fan, X., Mikolaenko, I., Elhassan, I., Ni, X., Wang, Y., Ball, D., Brat, D.J., Perry, A., and Eberhart, C.G. 2004. Notch1 and notch2 have opposite effects on embryonal brain tumor growth. Cancer Res. 64: 7787-7793.

Firth, L.C. and Baker, N.E. 2005. Extracellular signals responsible for spatially regulated proliferation in the differentiating Drosophila eye. Dev. Cell 8: 541-551.

Fisher, J., Piterman, N., Hubbard, E.J., Stern, M.J., and Harel, D. 2005. Computational insights into Caenorhabditis elegans vulval development. Proc. Natl. Acad. Sci. 102: 1951-1956.

Fitzgerald, K., Harrington, A., and Leder, P. 2000. Ras pathway signals are required for notch-mediated oncogenesis. Oncogene 19: 4191-4198.

Flores, G.V., Daga, A., Kalhor, H.R., and Banerjee, U. 1998. Lozenge is expressed in pluripotent precursor cells and patterns multiple cell types in the Drosophila eye through the control of cell-specific transcription factors. Development 125: 3681-3687.

Flores, G.V., Duan, H., Yan, H., Nagaraj, R., Fu, W., Zou, Y., Noll, M., and Banerjee, U. 2000. Combinatorial signaling in the specification of unique cell fates. Cell 103: 75-85.

Frankfort, B.J. and Mardon, G. 2002. R8 development in the Drosophila eye: A paradigm for neural selection and differentiation. Development 129: 1295-1306.

Freeman, M. 1994. The spitz gene is required for photoreceptor determination in the Drosophila eye where it interacts with the EGF receptor. Mech. Dev. 48: 25-33.

- 1996. Reiterative use of the EGF receptor triggers differentiation of all cell types in the Drosophila eye. Cell 87: 651-660.

Frise, E., Knoblich, J.A., Younger-Shepherd, S., Jan, L.Y., and Jan, Y.N. 1996. The Drosophila Numb protein inhibits signaling of the Notch receptor during cell-cell interaction in sensory organ lineage. Proc. Natl. Acad. Sci. 93: 11925-11932.

Fu, W. and Noll, M. 1997. The Pax2 homolog sparkling is required for development of cone and pigment cells in the Drosophila eye. [see comment]. Genes \& Dev. 11: 2066-2078.

Gabay, L., Scholz, H., Golembo, M., Klaes, A., Shilo, B.Z., and Klambt, C. 1996. EGF receptor signaling induces pointed P1 transcription and inactivates Yan protein in the Drosophila embryonic ventral ectoderm. Development 122: 3355-3362.

Gallahan, D. and Callahan, R. 1997. The mouse mammary tumor associated gene INT3 is a unique member of the NOTCH gene family (NOTCH4). Oncogene 14: 1883-1890.

Grant, K., Hanna-Rose, W., and Han, M. 2000. sem-4 promotes vulval cell-fate determination in Caenorhabditis elegans through regulation of lin-39 Hox. Dev. Biol. 224: 496-506.

Greenwald, I. 1998. LIN-12/Notch signaling: Lessons from worms and flies. Genes \& Dev. 12: 1751-1762.

Greenwald, I.S., Sternberg, P.W., and Horvitz, H.R. 1983. The lin-12 locus specifies cell fates in Caenorhabditis elegans. Cell 34: 435-444.

Greenwood, S. and Struhl, G. 1997. Different levels of Ras activity can specify distinct transcriptional and morphological consequences in early Drosophila embryos. Development 124: 4879-4886.

Halfar, K., Rommel, C., Stocker, H., and Hafen, E. 2001. Ras controls growth, survival and differentiation in the Drosophila eye by different thresholds of MAP kinase activity. Development 128: 1687-1696.

Halfon, M.S., Carmena, A., Gisselbrecht, S., Sackerson, C.M., Jimenez, F., Baylies, M.K., and Michelson, A.M. 2000. Ras pathway specificity is determined by the integration of multiple signal-activated and tissue-restricted transcription factors. Cell 103: 63-74.
Han, M., Aroian, R.V., and Sternberg, P.W. 1990. The let-60 locus controls the switch between vulval and nonvulval cell fates in Caenorhabditis elegans. Genetics 126: 899-913.

Haruki, N., Kawguchi, K.S., Eichenberger, S., Massion, P.P., Olson, S., Gonzalez, A., Carbone, D.P., and Dang, T.P. 2005. Dominant-negative Notch3 receptor inhibits mitogen-activated protein kinase pathway and the growth of human lung cancers. Cancer Res. 65: 3555-3561.

Hasson, P., Egoz, N., Winkler, C., Volohonsky, G., Jia, S., Dinur, T., Volk, T., Courey, A.J., and Paroush, Z. 2005. EGFR signaling attenuates Groucho-dependent repression to antagonize Notch transcriptional output. Nat. Genet. 37: 101-105.

Higashijima, S., Kojima, T., Michiue, T., Ishimaru, S., Emori, Y., and Saigo, K. 1992. Dual Bar homeo box genes of Drosophila required in two photoreceptor cells, R1 and R6, and primary pigment cells for normal eye development. Genes \& Dev. 6: $50-60$.

Hill, R.J. and Sternberg, P.W. 1992. The gene lin-3 encodes an inductive signal for vulval development in C. elegans [see comments]. Nature 358: 470-476.

Hopper, N.A., Lee, J., and Sternberg, P.W. 2000. ARK-1 inhibits EGFR signaling in C. elegans. Mol. Cell 6: 65-75.

Hori, K., Fostier, M., Ito, M., Fuwa, T.J., Go, M.J., Okano, H., Baron, M., and Matsuno, K. 2004. Drosophila deltex mediates suppressor of Hairless-independent and late-endosomal activation of Notch signaling. Development 131: 55275537.

Howard, R.M. and Sundaram, M.V. 2002. C. elegans EOR-1/ PLZF and EOR-2 positively regulate Ras and Wnt signaling and function redundantly with LIN-25 and the SUR-2 Mediator complex. Genes \& Dev. 16: 1815-1827.

Hubbard, E.J., Wu, G., Kitajewski, J., and Greenwald, I. 1997. sel-10, a negative regulator of lin-12 activity in Caenorhabditis elegans, encodes a member of the CDC4 family of proteins. Genes \& Dev. 11: 3182-3193.

Hwang, B.J. and Sternberg, P.W. 2004. A cell-specific enhancer that specifies lin-3 expression in the C. elegans anchor cell for vulval development. Development 131: 143-151.

Ikeya, T. and Hayashi, S. 1999. Interplay of Notch and FGF signaling restricts cell fate and MAPK activation in the Drosophila trachea. Development 126: 4455-4463.

Irvine, K.D. 1999. Fringe, Notch, and making developmental boundaries. Curr. Opin. Genet. Dev. 9: 434-441.

Iso, T., Kedes, L., and Hamamori, Y. 2003. HES and HERP families: Multiple effectors of the Notch signaling pathway. $J$. Cell. Physiol. 194: 237-255.

Jacobs, D., Beitel, G.J., Clark, S.G., Horvitz, H.R., and Kornfeld, K. 1998. Gain-of-function mutations in the Caenorhabditis elegans lin-1 ETS gene identify a C-terminal regulatory domain phosphorylated by ERK MAP kinase. Genetics 149: 1809-1822.

Jacobs, D., Glossip, D., Xing, H., Muslin, A.J., and Kornfeld, K. 1999. Multiple docking sites on substrate proteins form a modular system that mediates recognition by ERK MAP kinase. Genes \& Dev. 13: 163-175.

James, R.M., Arends, M.J., Plowman, S.J., Brooks, D.G., Miles, C.G., West, J.D., and Patek, C.E. 2003. K-ras proto-oncogene exhibits tumor suppressor activity as its absence promotes tumorigenesis in murine teratomas. Mol. Cancer Res. MCR 1: 820-825.

Jehn, B.M., Bielke, W., Pear, W.S., and Osborne, B.A. 1999. Cutting edge: Protective effects of notch-1 on TCR-induced apoptosis. J. Immunol. 162: 635-638.

Jhappan, C., Gallahan, D., Stahle, C., Chu, E., Smith, G.H., Merlino, G., and Callahan, R. 1992. Expression of an activated Notch-related int-3 transgene interferes with cell differen- 
tiation and induces neoplastic transformation in mammary and salivary glands. Genes \& Dev. 6: 345-355.

Johnson, S.M., Grosshans, H., Shingara, J., Byrom, M., Jarvis, R., Cheng, A., Labourier, E., Reinert, K.L., Brown, D., and Slack, F.J. 2005. RAS is regulated by the let-7 microRNA family. Cell 120: 635-647.

Kadesch, T. 2004. Notch signaling: The demise of elegant simplicity. Curr. Opin. Genet. Dev. 14: 506-512.

Kao, H.Y., Ordentlich, P., Koyano-Nakagawa, N., Tang, Z., Downes, M., Kintner, C.R., Evans, R.M., and Kadesch, T. 1998. A histone deacetylase corepressor complex regulates the Notch signal transduction pathway. Genes \& Dev. 12: 2269-2277.

Karp, X. and Greenwald, I. 2003. Post-transcriptional regulation of the E/Daughterless ortholog HLH-2, negative feedback, and birth order bias during the AC/VU decision in C. elegans. Genes \& Dev. 17: 3100-3111.

Katz, W.S., Hill, R.J., Clandinin, T.R., and Sternberg, P.W. 1995. Different levels of the C. elegans growth factor LIN-3 promote distinct vulval precursor fates. Cell 82: 297-307.

Kawamura, A., Koshida, S., Hijikata, H., Sakaguchi, T., Kondoh, H., and Takada, S. 2005. Zebrafish hairy/enhancer of split protein links FGF signaling to cyclic gene expression in the periodic segmentation of somites. Genes \& Dev. 19: 11561161.

Kiaris, H., Politi, K., Grimm, L.M., Szabolcs, M., Fisher, P., Efstratiadis, A., and Artavanis-Tsakonas, S. 2004. Modulation of notch signaling elicits signature tumors and inhibits hras1-induced oncogenesis in the mouse mammary epithelium. Am. J. Pathol. 165: 695-705.

Kimble, J. 1981. Alteration in cell lineage following laser ablation of cells in the somatic gonad of Caenorhabditis elegans. Dev. Biol. 87: 286-300.

Kitagawa, M., Oyama, T., Kawashima, T., Yedvobnick, B., Kumar, A., Matsuno, K., and Harigaya, K. 2001. A human protein with sequence similarity to Drosophila mastermind coordinates the nuclear form of notch and a CSL protein to build a transcriptional activator complex on target promoters. Mol. Cell. Biol. 21: 4337-4346.

Koh, K., Peyrot, S.M., Wood, C.G., Wagmaister, J.A., Maduro, M.F., Eisenmann, D.M., and Rothman, J.H. 2002. Cell fates and fusion in the C. elegans vulval primordium are regulated by the EGL-18 and ELT-6 GATA factors-Apparent direct targets of the LIN-39 Hox protein. Development 129: 51715180.

Kumar, J.P., Tio, M., Hsiung, F., Akopyan, S., Gabay, L., Seger, R., Shilo, B.Z., and Moses, K. 1998. Dissecting the roles of the Drosophila EGF receptor in eye development and MAP kinase activation. Development 125: 3875-3885.

Lai, E.C. 2002. Keeping a good pathway down: Transcriptional repression of Notch pathway target genes by CSL proteins. EMBO Rep. 3: 840-845.

Lefort, K. and Dotto, G.P. 2004. Notch signaling in the integrated control of keratinocyte growth/differentiation and tumor suppression. Semin. Cancer Biol. 14: 374-386.

Leight, E.R., Glossip, D., and Kornfeld, K. 2005. Sumoylation of LIN-1 promotes transcriptional repression and inhibition of vulval cell fates. Development 132: 1047-1056.

Levitan, D. and Greenwald, I. 1998. LIN-12 protein expression and localization during vulval development in C. elegans. Development 125: 3101-3109.

Lewis, T.S., Shapiro, P.S., and Ahn, N.G. 1998. Signal transduction through MAP kinase cascades. Adv. Cancer Res. 74: 49139.

Li, S., Li, Y., Carthew, R.W., and Lai, Z.C. 1997. Photoreceptor cell differentiation requires regulated proteolysis of the tran- scriptional repressor Tramtrack. Cell 90: 469-478.

Li, S., Xu, C., and Carthew, R.W. 2002. Phyllopod acts as an adaptor protein to link the sina ubiquitin ligase to the substrate protein tramtrack. Mol. Cell. Biol. 22: 6854-6865.

Ligoxygakis, P., Yu, S.Y., Delidakis, C., and Baker, N.E. 1998. A subset of notch functions during Drosophila eye development require $\mathrm{Su}(\mathrm{H})$ and the $\mathrm{E}(\mathrm{spl})$ gene complex. Development 125: 2893-2900.

Maloof, J.N. and Kenyon, C. 1998. The Hox gene lin-39 is required during $C$. elegans vulval induction to select the outcome of Ras signaling. Development 125: 181-190.

Malumbres, M. and Barbacid, M. 2002. RAS oncogenes: The first 30 years. Nat. Rev. Cancer 3: 7-13.

Marshall, C.J. 1995. Specificity of receptor tyrosine kinase signaling: Transient versus sustained extracellular signal-regulated kinase activation. Cell 80: 179-185.

Martinez Arias, A., Zecchini, V., and Brennan, K. 2002. CSLindependent Notch signalling: A checkpoint in cell fate decisions during development? Curr. Opin. Genet. Dev. 12: 524-533.

Matheny, S.A., Chen, C., Kortum, R.L., Razidlo, G.L., Lewis, R.E., and White, M.A. 2004. Ras regulates the assembly of mitogenic signalling complexes through the effector protein IMP. Nature 427: 256-259.

Miller, L.M., Gallegos, M.E., Morisseau, B.A., and Kim, S. 1993. Lin-31, a Caenorhabditis elegans HNF-3/forkhead transcription factor homolog, specificies three alternative cell fates in vulval development. Genes \& Dev. 7: 933-947.

Morimura, T., Goitsuka, R., Zhang, Y., Saito, I., Reth, M., and Kitamura, D. 2000. Cell cycle arrest and apoptosis induced by Notch1 in B cells. J. Biol. Chem. 275: 36523-36531.

Morrison, D.K. and Davis, R.J. 2003. Regulation of MAP kinase signaling modules by scaffold proteins in mammals. Annu. Rev. Cell Dev. Biol. 19: 91-118.

Murphy, L.O., Smith, S., Chen, R.H., Fingar, D.C., and Blenis, J. 2002. Molecular interpretation of ERK signal duration by immediate early gene products. [see comment]. Nat. Cell Biol. 4: 556-564.

Murphy, L.O., MacKeigan, J.P., and Blenis, J. 2004. A network of immediate early gene products propagates subtle differences in mitogen-activated protein kinase signal amplitude and duration. Mol. Cell. Biol. 24: 144-153.

Nellesen, D.T., Lai, E.C., and Posakony, J.W. 1999. Discrete enhancer elements mediate selective responsiveness of enhancer of split complex genes to common transcriptional activators. Dev. Biol. 213: 33-53.

Neves, A. and Priess, J.R. 2005. The REF-1 family of bHLH transcription factors pattern C. elegans embryos through Notch-dependent and Notch-independent pathways. Dev. Cell 8: 867-879.

Nicolas, M., Wolfer, A., Raj, K., Kummer, J.A., Mill, P., van Noort, M., Hui, C.C., Clevers, H., Dotto, G.P., and Radtke, F. 2003. Notch1 functions as a tumor suppressor in mouse skin. Nat. Genet. 33: 416-421.

$\mathrm{O}^{\prime}$ Neill, E. and Kolch, W. 2004. Conferring specificity on the ubiquitous Raf/MEK signalling pathway. Br. J. Cancer 90: 283-288.

O'Neill, E.M., Rebay, I., Tijan, R., and Rubin, G.M. 1994. The activities of two Ets-related transcription factors required for Drosophila eye development are modulated by the Ras/ MAPK pathway. Cell 78: 137-147.

Okuyama, R., Nguyen, B.C., Talora, C., Ogawa, E., Tommasi di Vignano, A., Lioumi, M., Chiorino, G., Tagami, H., Woo, M., and Dotto, G.P. 2004. High commitment of embryonic keratinocytes to terminal differentiation through a Notch1caspase 3 regulatory mechanism. Dev. Cell 6: 551-562. 
Pear, W.S., Aster, J.C., Scott, M.L., Hasserjian, R.P., Soffer, B., Sklar, J., and Baltimore, D. 1996. Exclusive development of T cell neoplasms in mice transplanted with bone marrow expressing activated Notch alleles. I. Exp. Med. 183: 22832291.

Petcherski, A.G. and Kimble, J. 2000. LAG-3 is a putative transcriptional activator in the C. elegans Notch pathway. $\mathrm{Na}$ ture 405: 364-368.

Prober, D.A. and Edgar, B.A. 2000. Ras1 promotes cellular growth in the Drosophila wing. Cell 100: 435-446.

- 2002. Interactions between Ras1, dMyc, and dPI3K signaling in the developing Drosophila wing. Genes \& Dev. 16: $2286-2299$.

Pullikuth, A., McKinnon, E., Schaeffer, H.J., and Catling, A.D. 2005. The MEK1 scaffolding protein MP1 regulates cell spreading by integrating PAK1 and Rho signals. Mol. Cell. Biol. 25: 5119-5133.

Qiao, F., Song, H., Kim, C.A., Sawaya, M.R., Hunter, J.B., Gingery, M., Rebay, I., Courey, A.J., and Bowie, J.U. 2004. Derepression by depolymerization; structural insights into the regulation of Yan by Mae. Cell 118: 163-173.

Radtke, F. and Raj, K. 2003. The role of Notch in tumorigenesis: Oncogene or tumour suppressor? Nat. Rev. Cancer 3: 756767.

Ramain, P., Khechumian, K., Seugnet, L., Arbogast, N., Ackermann, C., and Heitzler, P. 2001. Novel Notch alleles reveal a Deltex-dependent pathway repressing neural fate. Curr. Biol. 11: 1729-1738.

Rangarajan, A., Talora, C., Okuyama, R., Nicolas, M., Mammucari, C., Oh, H., Aster, J.C., Krishna, S., Metzger, D., Chambon, P., et al. 2001. Notch signaling is a direct determinant of keratinocyte growth arrest and entry into differentiation. EMBO J. 20: 3427-3436.

Rebay, I. and Rubin, G.M. 1995. Yan functions as a general inhibitor of differentiation and is negatively regulated by activation of the Ras1/MAPK pathway. Cell 81: 857-866.

Repasky, G.A., Chenette, E.J., and Der, C.J. 2004. Renewing the conspiracy theory debate: Does Raf function alone to mediate Ras oncogenesis? Trends Cell Biol. 14: 639-647.

Rodriguez-Viciana, P., Sabatier, C., and McCormick, F. 2004. Signaling specificity by Ras family GTPases is determined by the full spectrum of effectors they regulate. Mol. Cell. Biol. 24: 4943-4954.

Rohrbaugh, M., Ramos, E., Nguyen, D., Price, M., Wen, Y., and Lai, Z.C. 2002. Notch activation of yan expression is antagonized by RTK/pointed signaling in the Drosophila eye. Curr. Biol. 12: 576-581.

Sabbagh Jr., W., Flatauer, L.J., Bardwell, A.J., and Bardwell, L. 2001. Specificity of MAP kinase signaling in yeast differentiation involves transient versus sustained MAPK activation. Mol. Cell 8: 683-691.

Schlessinger, J. 2000. Cell signaling by receptor tyrosine kinases. [see comments]. Cell 103: 211-225.

Serrano, M., Lin, A.W., McCurrach, M.E., Beach, D., and Lowe, S.W. 1997. Oncogenic ras provokes premature cell senescence associated with accumulation of p53 and p16INK4a. Cell 88: 593-602.

Sharrocks, A.D. 2001. The ETS-domain transcription factor family. Nat. Rev. Mol. Cell. Biol. 2: 827-837.

Shaye, D.D. and Greenwald, I. 2002. Endocytosis-mediated downregulation of LIN-12/Notch upon Ras activation in Caenorhabditis elegans. Nature 420: 686-690.

Simon, M.A. 2000. Receptor tyrosine kinases: Specific outcomes from general signals. Cell 103: 13-15.

Simon, M.A., Bowtell, D.D.L., Dodson, G.S., Laverty, T.R., and Rubin, G.M. 1991. Ras1 and a putative guanine nucleotide exchange factor perform crucial steps in signaling by the Sevenless protein tyrosine kinase. Cell 67: 701-716.

Simske, J.S. and Kim, S.K. 1995. Sequential signalling during Caenorhabditis elegans vulval induction. Nature 375: 142146.

Singh, N. and Han, M. 1995. sur-2, a novel gene, functions late in the let-60 ras-mediated signaling pathway during Caenorhabditis elegans vulval induction. Genes \& Dev. 9: 2251-2265.

Singh, A., Sowjanya, A.P., and Ramakrishna, G. 2005. The wildtype Ras: Road ahead. FASEB J. 19: 161-169.

Small, D., Kovalenko, D., Soldi, R., Mandinova, A., Kolev, V., Trifonova, R., Bagala, C., Kacer, D., Battelli, C., Liaw, L., et al. 2003. Notch activation suppresses fibroblast growth factor-dependent cellular transformation. J. Biol. Chem. 278: 16405-16413.

Song, H., Nie, M., Qiao, F., Bowie, J.U., and Courey, A.J. 2005. Antagonistic regulation of Yan nuclear export by Mae and Crm1 may increase the stringency of the Ras response. Genes \& Dev. 19: 1767-1772.

Stella, M.C., Trusolino, L., Pennaccheitti, S., and Comoglio, P.M. 2005. Negative feedback regulation of met-dependent invasive growth by notch. Mol. Cell. Biol. 25: 3982-3996.

Sternberg, P.W. 1988. Lateral inhibition during vulval induction in Caenorhabditis elegans. Nature 335: 551-554.

- 2005. Vulva development. In Wormbook (eds. The C. elegans Research Community) WormBook. http://www. wormbook.org (accession date July 2005).

Sternberg, P.W. and Horvitz, H.R. 1989. The combined action of two intercellular signaling pathways specifies three cell fates during vulval induction in C. elegans. Cell 58: 679-693.

Stevens, J.L., Cantin, G.T., Wang, G., Shevchenko, A., and Berk, A.J. 2002. Transcription control by E1A and MAP kinase pathway via Sur2 mediator subunit. Science 296: 755-758.

Sundaram, M.V. 2004. Vulval development: The battle between Ras and Notch. Curr. Biol. 14: R311-R313.

- 2005. RTK-Ras-ERK signaling in C. elegans. In Wormbook (eds. The C. elegans Research Community) WormBook. http://www.wormbook.org (accession date July 2005).

Tan, P. and Kim, S.K. 1999. Signaling specificity: The RTK/Ras/ MAP kinase pathway in metazoans. Trends Genet. 15: 145149.

Tan, P.B., Lackner, M.R., and Kim, S.K. 1998. MAP kinase signaling specificity mediated by the LIN-1 Ets/LIN-31 WH transcription factor complex during C. elegans vulval induction. Cell 93: 569-580.

Tang, A.H., Neufeld, T.P., Kwan, E., and Rubin, G.M. 1997. PHYL acts to down-regulate TTK88, a transcriptional repressor of neuronal cell fates, by a SINA-dependent mechanism. Cell 90: 459-467.

Teis, D., Wunderlich, W., and Huber, L.A. 2002. Localization of the MP1-MAPK scaffold complex to endosomes is mediated by p14 and required for signal transduction. Dev. Cell 3: 803-814.

Tio, M., Ma, C., and Moses, K. 1994. spitz, a Drosophila homo$\log$ of transforming growth factor- $\alpha$, is required in the founding photoreceptor cells of the compound eye facets. Mech. Dev. 48: 13-23.

Tomlinson, A. and Ready, D.F. 1987. Cell fate in the Drosophila ommatidium. Dev. Biol. 123: 264-275.

Tomlinson, A. and Struhl, G. 2001. Delta/Notch and Boss/Sevenless signals act combinatorially to specify the Drosophila R7 photoreceptor. Mol. Cell 7: 487-495.

Tootle, T.L., Lee, P.S., and Rebay, I. 2003. CRM1-mediated nuclear export and regulated activity of the Receptor Tyrosine Kinase antagonist YAN require specific interactions 
with MAE. Development 130: 845-857.

Tsruya, R., Schlesinger, A., Reich, A., Gabay, L., Sapir, A., and Shilo, B.Z. 2002. Intracellular trafficking by Star regulates cleavage of the Drosophila EGF receptor ligand Spitz. Genes \& Dev. 16: 222-234.

Tsuda, L., Nagaraj, R., Zipursky, S.L., and Banerjee, U. 2002. An EGFR/Ebi/Sno pathway promotes $\delta$ expression by inactivating $\mathrm{Su}(\mathrm{H}) / \mathrm{SMRTER}$ repression during inductive notch signaling. Cell 110: 625-637.

Tuck, S. and Greenwald, I. 1995. lin-25, a gene required for vulval induction in Caenorhabditis elegans. Genes \& Dev. 9: 341-357.

Urban, S., Lee, J.R., and Freeman, M. 2002. A family of Rhomboid intramembrane proteases activates all Drosophila membrane-tethered EGF ligands. EMBO J. 21: 4277-4286.

Vivekanand, P., Tootle, T.L., and Rebay, I. 2004. MAE, a dual regulator of the EGFR signaling pathway, is a target of the Ets transcription factors PNT and YAN. Mech. Dev. 121: 1469-1479.

Voas, M.G. and Rebay, I. 2004. Signal integration during development: Insights from the Drosophila eye. Dev. Dyn. 229: $162-175$.

Wassarman, D.A., Therrien, M., and Rubin, G.M. 1995. The Ras signaling pathway in Drosophila. Curr. Opin. Gen. Dev. 5: 44-50.

Wasserman, J.D., Urban, S., and Freeman, M. 2000. A family of rhomboid-like genes: Drosophila rhomboid-1 and roughoid/ rhomboid-3 cooperate to activate EGF receptor signaling. Genes \& Dev. 14: 1651-1663.

Weijzen, S., Rizzo, P., Braid, M., Vaishnav, R., Jonkheer, S.M., Zlobin, A., Osborne, B.A., Gottipati, S., Aster, J.C., Hahn, W.C., et al. 2002. Activation of Notch-1 signaling maintains the neoplastic phenotype in human Ras-transformed cells. Nat. Med. 8: 979-986.

Weng, A.P., Ferrando, A.A., Lee, W., Morris IV, J.P., Silverman, L.B., Sanchez-Irizarry, C., Blacklow, S.C., Look, A.T., and Aster, J.C. 2004. Activating mutations of NOTCH1 in human T cell acute lymphoblastic leukemia. Science 306: 269271.

Wilkinson, H.A., Fitzgerald, K., and Greenwald, I. 1994. Reciprocal changes in expression of the receptor lin-12 and its ligand lag-2 prior to commitment in a C. elegans cell fate decision. Cell 79: 1187-1198.

Wu, L., Aster, J.C., Blacklow, S.C., Lake, R., Artavanis-Tsakonas, S., and Griffin, J.D. 2000. MAML1, a human homologue of Drosophila mastermind, is a transcriptional co-activator for NOTCH receptors. Nat. Genet. 26: 484-489.

Xiong, W.C. and Montell, C. 1993. tramtrack is a transcriptional repressor required for cell fate determination in the Drosophila eye. Genes \& Dev. 7: 1085-1096.

$\mathrm{Xu}, \mathrm{T}$. and Rubin, G.M. 1993. Analysis of genetic mosaics in developing and adult Drosophila tissues. Development 117: 1223-1237.

Xu, C., Kauffmann, R.C., Zhang, J., Kladny, S., and Carthew, R.W. 2000. Overlapping activators and repressors delimit transcriptional response to receptor tyrosine kinase signals in the Drosophila eye. Cell 103: 87-97.

Yang, L. and Baker, N.E. 2001. Role of the EGFR/Ras/Raf pathway in specification of photoreceptor cells in the Drosophila retina. Development 128: 1183-1191.

Yang, S.H. and Sharrocks, A.D. 2004. SUMO promotes HDACmediated transcriptional repression. Mol. Cell 13: 611-617.

Yang, S.H., Jaffray, E., Hay, R.T., and Sharrocks, A.D. 2003. Dynamic interplay of the SUMO and ERK pathways in regulating Elk-1 transcriptional activity. Mol. Cell 12: 63-74.

Yeung, K., Seitz, T., Li, S., Janosch, P., McFerran, B., Kaiser, C.,
Fee, F., Katsanakis, K.D., Rose, D.W., Mischak, H., et al. 1999. Suppression of Raf-1 kinase activity and MAP kinase signalling by RKIP. Nature 401: 173-177.

Yochem, J., Sundaram, M., and Han, M. 1997. Ras is required for a limited number of cell fates and not for general proliferation in Caenorhabditis elegans. Mol. Cell. Biol. 17: 27162722.

Yoo, A.S., Bais, C., and Greenwald, I. 2004. Crosstalk between the EGFR and LIN-12/Notch pathways in C. elegans vulval development. Science 303: 663-666.

Zhang, Z., Wang, Y., Vikis, H.G., Johnson, L., Liu, G., Li, J., Anderson, M.W., Sills, R.C., Hong, H.L., Devereux, T.R., et al. 2001. Wildtype Kras2 can inhibit lung carcinogenesis in mice. Nat. Genet. 29: 25-33.

zur Lage, P. and Jarman, A.P. 1999. Antagonism of EGFR and notch signalling in the reiterative recruitment of Drosophila adult chordotonal sense organ precursors. Development 126: $3149-3157$ 


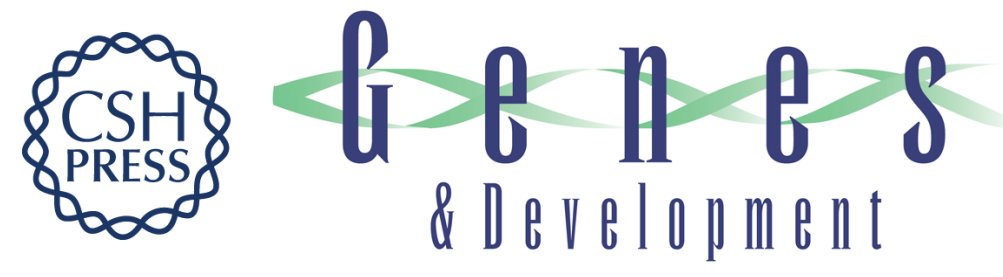

\section{The love-hate relationship between Ras and Notch}

Meera V. Sundaram

Genes Dev. 2005, 19:

Access the most recent version at doi:10.1101/gad.1330605

References This article cites 172 articles, 72 of which can be accessed free at: http://genesdev.cshlp.org/content/19/16/1825.full.html\#ref-list-1

License

Email Alerting Receive free email alerts when new articles cite this article - sign up in the box at the top Service right corner of the article or click here.

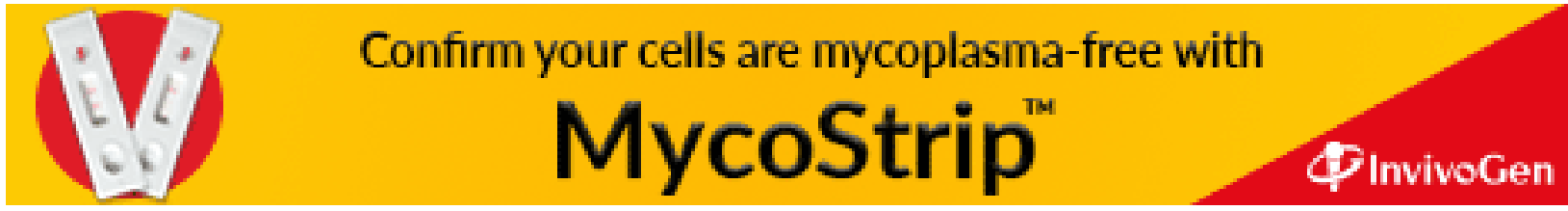

